\title{
OPTIMIZING THE MONITORING OF NATURAL PHENOMENA THROUGH THE COUPLING OF ORBITAL MULTI-SENSORS
}

\author{
OTIMIZAÇÃO DO MONITORAMENTO DE FENÔMENOS NATURAIS POR MEIO DO ACOPLAMENTO DE \\ MULTISENSORES ORBITAIS
}

\begin{abstract}
High frequency of images and high spatial resolution are necessary characteristics in studies with high temporal and spatial dynamics, which are difficult to find in a single orbital sensor. Therefore, the possibility of using multiple satellites to overcome this obstacle in monitoring is of fundamental importance. The aim of the study was to evaluate the multi-sensor coupling for the monitoring of phenomena that require a greater frequency of spatial detail and high-temporal observations by intercalibrating the reflectance images of the LISS III sensor, which is on board the satellite ResourceSat-II, and the MSI sensor onboard the Sentinel-2A, utilizing the Landsat-8 OLI sensor as standard. To perform the methodology, prior the intercalibration, it was necessary to convert the digital numbers of the bands into reflectance at the top of the atmosphere, so that intercalibration of data with simple linear regression could be subsequently performed. The results demonstrate that, with the intercalibrations of the reflectance images of the LISS III and MSI sensors, it is possible to couple the information of these sensors with those coming from OLI, enabling the increase of the frequency and availability of information in studies that require more observations, as in agricultural monitoring, natural disasters, and deforestation among others.
\end{abstract}

Keywords: Temporal resolution. multiple sensors. availability of images.

\section{RESUMO}

Alta frequência de imagens e resolução espacial são características necessárias em estudos com alta dinâmica temporal e espacial, difícil de encontrar em um único sensor orbital. Portanto, a possibilidade de usar vários satélites para solucionar esse obstáculo no monitoramento é de fundamental importância. O objetivo do estudo foi avaliar o acoplamento multisensor para monitorar fenômenos que requerem uma frequência mais elevada de imagens detalhadas, intercalando as imagens de reflectância do sensor LISS III, a bordo do satélite ResourceSat-II e o sensor MSI no Sentinel-2A, utilizando o sensor OLI (Landsat-8) como padrão. Para prosseguir com a metodologia, foi necessário, antes da intercalibração, converter os números digitais (bandas) em refletância no topo da atmosfera, para que posteriormente fosse possível realizar a intercalibração dos dados com regressão linear simples. Os resultados demonstram que, com a intercalibração das imagens de reflectância dos sensores LISS III e MSI, é possível acoplar as informações desses sensores com as provenientes do OLI, possibilitando o aumento da frequência e disponibilidade de informações em estudos que exigem mais observações, como no monitoramento agrícola, desastres naturais e desmatamento, entre outros.

Palavras-chave: Resolução temporal; múltiplos sensores; disponibilidade de imagens.

\author{
Roberto Filgueiras ${ }^{\text {a }}$ \\ Everardo Chartuni Mantovani ${ }^{\text {a }}$ \\ Santos Henrique Brant Dias ${ }^{b}$ \\ Delpídio Inácio Fernandes Filho ${ }^{a}$ \\ Dernando França da Cunha ${ }^{a}$ \\ ${ }^{\text {a }}$ Universidade Federal de Viçosa (UFV), \\ Viçosa, MG, Brasil \\ ${ }^{\text {b }}$ Universidade Estadual de Ponta Grossa \\ (UEPG), Ponta Grossa, PR, Brasil
}

DOI: $10.12957 /$ geouerj.2020.37832

Correpondência: betofilgueiras@gmail.com

Recebido em: 16 out. 2018

Revisado em: 10 out. 2020

Aceito em: 11 nov.2020

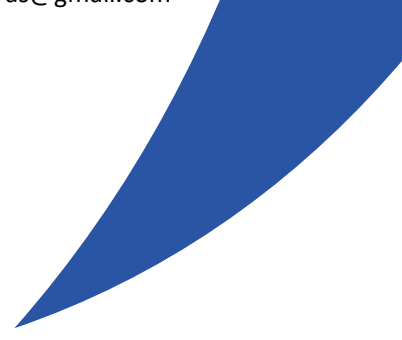




\section{INTRODUÇÃO}

With the current need for food, continuous and detailed monitoring of agriculture is essential, and this process requires images with high spatial and temporal resolution, which are hardly present in a single sensor (Jensen; Epiphanio, 2011). Phenological changes, especially in annual crops, happen quickly, making a high temporal resolution necessary (Bertolin et al., 2017).

In order to monitor vegetation along the time series, it is advantageous to use multiple sensors because, for the same range of the spectrum, different sensors have different spectral response values (Fan; Liu, 2017), mainly due to the configurations and calibrations that are unique in each sensor and become necessary for inter-sensor calibration (D’Odorico et al., 2013; Fan; Liu, 2017; Mao et al., 2012; Teillet et al., 2001). Mao et al. (2012) point out that these discrepancies occur mainly due to the spectral amplitude of the electromagnetic radiation captured, temporal differences related to the passage of the sensors, and spatial resolution.

During the data acquisition by orbital sensors, there are several factors that cause radiometric distortions in the images, such as differences in atmospheric conditions, lighting, sighting angles, among others (Balthazar; Vanacker; Lambin, 2012; Lima; Ribeiro, 2014; Szantoi; Simonetti, 2013; Teillet; Guindon; Goodenough, 1982). For some applications, the attenuation of these distortions is an indispensable process; on the other hand, in many situations, the processes involving radiometric corrections are not a trivial task, especially when the procedure involves the knowledge of factors that cause such distortions, which are not always available. If the intention is to monitor a certain spatial and temporal phenomenon, these considerations are essential and must be complied (Colby, 1991; Gao; Kustas; Anderson, 2012; Hantson; Chuvieco, 2011; Jiménez-Muñoz et al., 2010; Kobayashi; Sanga-Ngoie, 2009; Riano et al., 2003).

Images from free platforms such as ResourceSat-II/LISS III, Landsat-8/OLI, and Sentinel-2A/MSI have spatial resolution that allows carrying out observations at the farm level. These are detailed observations but, when higher frequency images are desired, the temporal resolution of each platform is limited. The ResourceSat-II/LISS III temporal resolution is 24 days, while the values for Landsat-8/OLI and Sentinel-2A are 16 days and 10 days, respectively (Drusch et al., 2012; Navalgund; Jayaraman; Roy, 2007; Roy et al., 2014). In addition to low temporal resolutions, there is still the issue of the availability of information due to the presence of clouds, which reduces the availability of images from the optical spectrum, leaving them limited in terms of analysis and extraction of information (Chen et al., 2017).

However, if they are used in an integrated way, that is, with one satellite complementing the information of the other, this obstacle can be overcome. Thus, a higher frequency of images would be obtained, making it possible to perceive and monitor the phenological dynamics of the agricultural crops and even to infer about questions related to irrigation management. However, in order to have the possibility of 
monitoring using multi-sensors, their data need to be compatible with each other, so it is important to perform an intercalibration between the sensors to be coupled (Fan; Liu, 2017; Li; Jiang; Feng, 2013; Yan et al., 2016).

Researchers and decision makers often deal with multiple sensors to solve and observe issues in their areas and, because of this, it is important to know the compatibility of data acquisition between sensors and the possibility of calibrating their readings (Chander et al., 2009; Pandya; Murali; Kirankumar, 2013).

Based on the possibility of using multiple satellites to increase the frequency and availability of images for agricultural monitoring, this study aimed to intercalibrate the reflectance images of the LISS III sensor, which is onboard the ResourceSat-II satellite and the MSI sensor, onboard the Sentinel-2A, as a function of the Landsat-8 OLI sensor. These intercalibrations will be referred to in the present study as: OLI x LISSIII and OLI x MSI, respectively.

\section{MATERIALS AND METHODS}

\section{Area used for sensor intercalibration}

The area used for the intercalibration of Sentinel-2A/MSI and ResourceSat-II/LISS III images, based on images from the Landsat-8/OLI platform, is inserted in the central-west portion of the state of Minas Gerais, Brazil (Figure 1), between the coordinates X1-502741.80; Y1-7898534.80 and X2-590056.20; Y2-7809508.34 S, WGS-84 datum, UTM (Universal Transverse Mercator) projection, 23S zone. This area was selected because of its heterogeneous land use, which results in greater amplitude in the reflectance values used in the intercalibration and, as consequence, leads to models with more capability of generalization. The area includes bare soil, planted forest, native forest, agriculture, pasture, urban area, rivers and lakes.

Figure 1. Location of the areas used to intercalibrate the LISS III and MSI sensors, as a function of the OLI sensor.
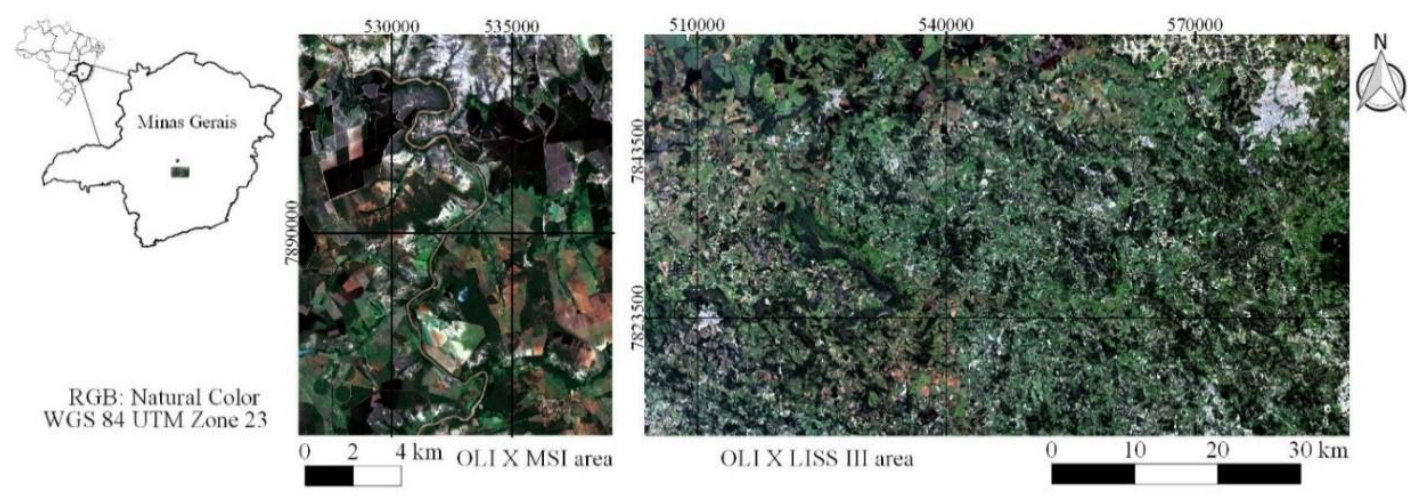

Source: authors. 
The OLI x LISS III intercalibration was performed using images of March 13, 2017, for both sensors, LISS III orbit/point 332/091, which corresponds to the OLI sensor's orbit/point 218/074. The OLI x MSI intercalibration was performed using images of December 23, 2016 for both sensors. The image used from the MSI sensor was the 23KNU, which corresponded to the OLI sensor's orbit/point 218/074.

\section{Orbital Platforms}

The intercalibration of the data is based on three orbital platforms, the Landsat- 8 , which served as the modeling standard, and as independent variables the Sentinel-2A and the ResourceSat-II platforms. The Landsat-8 platform was established as a standard because it belonged to the constellation that captured the Earth's surface for the longest time and also for its wide use and tradition in scientific research (Wulder et al. 2019).

Landsat-8 has two sensors, the Operational Land Image (OLI) and the Thermal Infrared Sensor (TIRS) (Irons; Dwyer; Barsi, 2012; Roy et al., 2014) with a temporal resolution of 16 days and radiometric resolution of 16 bits.

The ResourceSat-II is equipped with LISS III (Linear Imaging Self-Scanning Sensor-3) sensor, with spatial resolution of 23.5 meters, with four spectral bands (Table 1), and image width of $141 \mathrm{~km}$, with a radiometric resolution of 10 bits (Seth et al., 2016) and temporal resolution of 24 days.

The Sentinel-2A satellite, whose sensor is the MSI (MultiSpectral Imager), has spatial resolution varying from 10 to 60 meters in 13 spectral bands (Fernández-Manso; Fernández-Manso; Quintano, 2016), temporal resolution of 10 days and radiometric resolution of 12 bits. The characteristics of the spectral bands common to the three sensors are shown in Table 1.

Table 1. Description of LISS III, OLI and MSI sensor bands.

\begin{tabular}{|c|c|c|c|c|c|c|c|c|}
\hline \multicolumn{3}{|l|}{ LISS III } & \multicolumn{3}{|l|}{ OLI } & \multicolumn{3}{|l|}{ MSI } \\
\hline Bands & $(\mu \mathrm{m})$ & $\begin{array}{l}\text { Spatial } \\
\text { res. }(\mathrm{m})\end{array}$ & Bands & $(\mu \mathrm{m})$ & Spatial res. (m) & Bands & $(\mu \mathrm{m})$ & Spatial res. (m) \\
\hline- & - & - & B2 & $0.45-0.51$ & 30 & B02 & $0.45-0.52$ & 10 \\
\hline B2 & $0.52-0.59$ & 23.5 & B3 & $0.53-0.59$ & 30 & B03 & $0.54-0.58$ & 10 \\
\hline B3 & $0.62-0.68$ & 23.5 & B4 & $0.64-0.67$ & 30 & B04 & $0.65-0.68$ & 10 \\
\hline B4 & $0.77-0.86$ & 23.5 & B5 & $0.85-0.88$ & 30 & B08 & $0.78-0.90$ & 10 \\
\hline B5 & $1.55-1.70$ & 23.5 & B6 & $1.57-1.65$ & 30 & B11 & $1.57-1.66$ & 20 \\
\hline- & - & - & B7 & $2.11-2.29$ & 30 & B12 & $2.10-2.28$ & 20 \\
\hline
\end{tabular}

Spatial res. = Spatial resolution

Source: Pandya; Murali; Kirankumar (2013); Drusch et al. (2012); Roy et al. (2014) 


\section{Intercalibration process}

In order to proceed with the intercalibration of the spectral bands OLI/ LISS III, the image from the LISS III sensor needed to be previously georeferenced using the Landsat- 8 image as the baseline and the conversion of digital numbers (DN) to reflectance for both sensors. The conversion is necessary to compare the instruments from a physical reference (Ponzoni; Shimabukuro; Kuplich, 2012). The LISS III conversion was performed in two stages: conversion of DN to spectral radiance, following the methodology proposed by Seth et al. (2016), and then conversion to reflectance at the top of the atmosphere, through Equation 1.

$$
\rho_{\lambda \mathrm{i}}=\frac{\Pi L_{\lambda \mathrm{i}}}{K_{\lambda \mathrm{i}} \cdot \cos Z \cdot d r}
$$

where $\rho_{\lambda i}$ is the reflectance for band $\mathrm{i} ; Z$ is the zenith angle, $K_{\lambda i}$ is the spectral irradiance at the top of the atmosphere for each band $\left(\mathrm{W} \mathrm{m}^{-2} \mu^{-1}\right)$ present in Table 2, $d r$ is the inverse of the square of the Earth-Sun distance in astronomical units, calculated from Julian day of the images, and $L_{\lambda i}\left(\mathrm{~W} \mathrm{~m}^{-2} \mathrm{sr}^{-1} \mu \mathrm{m}^{-1}\right)$ is the spectral radiance for each band.

Table 2. Irradiance at the top of the atmosphere for the LISS III sensor.

\begin{tabular}{ll}
\hline Bands & K $\lambda$ i (LISS III) \\
\hline B2 - Green & 1846.77 \\
B3 - Red & 1575.50 \\
B4 - NIR & 1087.34 \\
B5 - SWIR & 236,65 \\
\hline
\end{tabular}

Source: Pandya et al., 2007, 2002; Zhang and Tian, 2015.

The digital numbers of the OLI sensor bands were converted to reflectance, also in two stages. However, for the conversion of DN to planetary reflectance, Equation 2 was used. After that, Equation 3 was used to obtain the parameter reflectance at the top of the atmosphere, corrected by the zenith angle, for each spectral band of interest. (Ariza, 2013)

$$
\rho_{\lambda}^{\prime}=M_{p} Q_{c a l}+A_{p}
$$


where: $\rho_{\lambda}^{\prime}$ is the planetary reflectance, without correction of the solar angle; $\mathrm{M}_{\rho}$ is the multiplicative factor of each band, found in the metadata file (REFLECTANCE_MULT_BAND_i, where $i$ is the band number); $A_{P}$ is the addition coefficient found in the metadata file (REFLECTANCE_ADD_BAND_i, where i refers to the band number); and $Q_{c a l}$ are the digital numbers (DN) corresponding to each band of the image. Besides, it is necessary to correct the reflectance according to zenith angle, which was performed using Equation 3 (Ariza, 2013).

$$
\rho_{\lambda}=\frac{\rho_{\rho}^{\prime}}{\cos \left(\theta_{\mathrm{SZ}}\right)}=\frac{\rho_{\rho}^{\prime}}{\sin \left(\Theta_{\mathrm{SE}}\right)}
$$

where $\rho_{\lambda}$ is the planetary reflectance, with zenith angle correction, $\theta_{S E}$ is the solar elevation angle, and $\theta_{S Z}$ is the solar zenith angle, present in the MTL file.

Figure 2. Calibration process of the LISS III sensor bands in relation to OLI sensor bands.

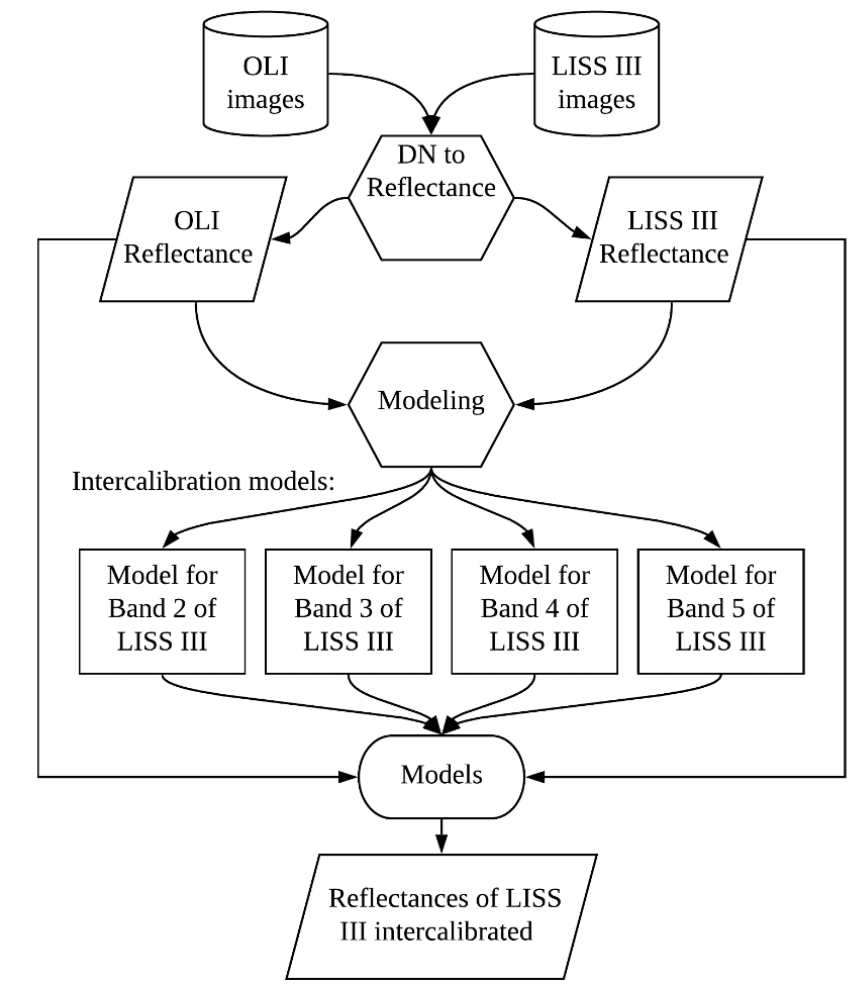

Source: authors. 
For the modeling of the bands present in the MSI sensor, with those of the OLI sensor, the same procedures were required. However, the MSI sensor bands are already in values of reflectance at the top of the atmosphere, but these data are rescaled, so it is necessary to multiply them by a quantification value, present in the Metadata file, to obtain the values of reflectance at the top of the atmosphere within the range between 0 and 1 (Gascon et al., 2017).

After the aforementioned processing, the compatible bands of both sensors were modeled, so that an equation could be found for the reflectance of each MSI band that converted them into reflectance referring to the OLI/Landsat-8 sensor bands, according to Figure 3.

Figure 3. Calibration process of the MSI sensor bands in relation to OLI sensor bands

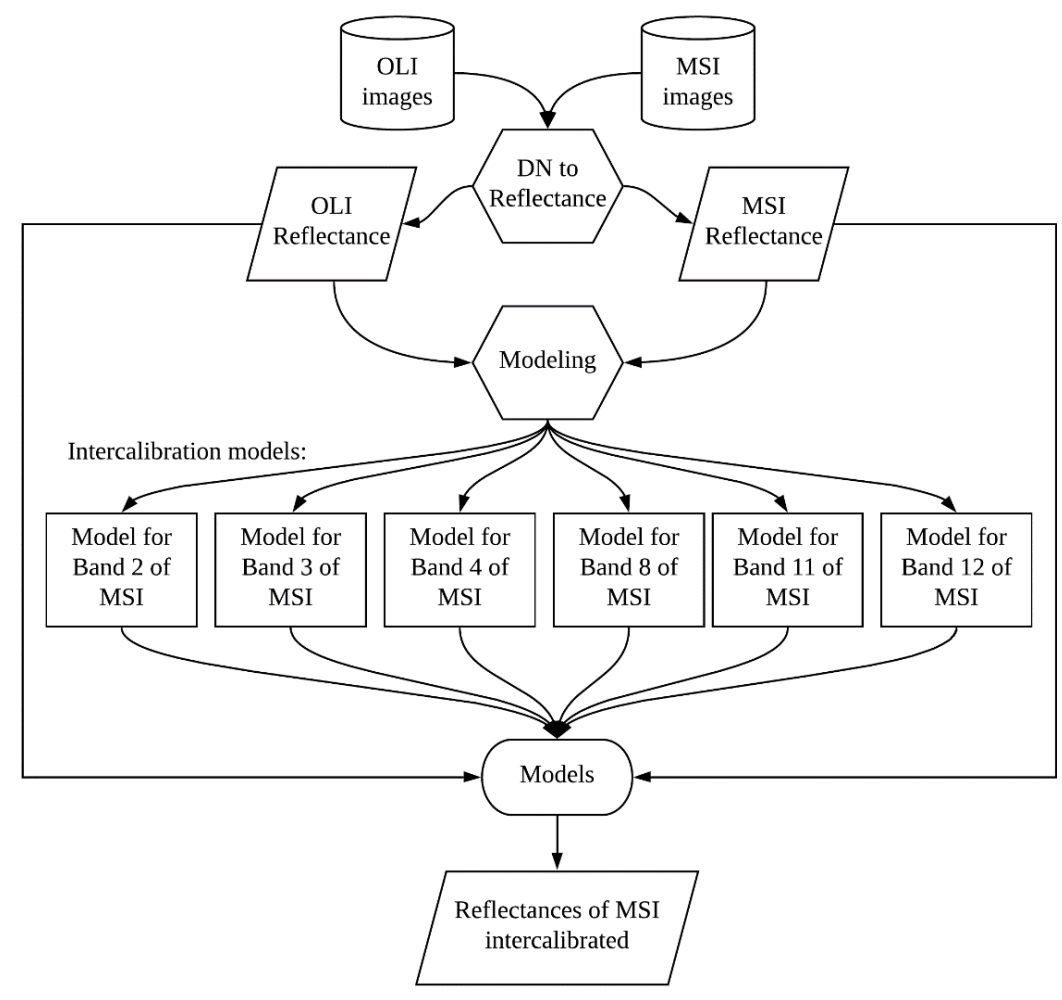

Source: authors.

Since both variables, the dependent and the independent, are reflectance data and come from highquality sensors, the assumption was that a simple linear regression would fit to the data. In this way, simple linear regression models were tested and adjusted for both LISS III and MSI sensors (independent variables) as a function of OLI (dependent variable), as described in Equation 4 and Equation 5.

$$
\rho_{\mathrm{OLI}}=\beta_{\mathrm{o}}+\beta_{i}^{*} \rho_{\mathrm{LISSII}}
$$




$$
\rho_{\mathrm{OLI}}=\beta_{\mathrm{o}}+\beta_{i} * \rho_{\mathrm{MSI}}
$$

where $\rho_{\text {(OLI; LISSII; MSI) }}$ are the reflectances of the sensors, while $\beta_{\mathrm{o}}$ and $\beta_{\mathrm{i}}$ are the coefficients of the regression.

All the process of intercalibration between sensors was executed with QGIS 2.8 and R.

\section{Training and validation sample set}

In order to calibrate the LISS III and MSI sensors, two regular sets of 50.000 points were generated, one for the area used to calibrate the LISS III $\left(4060 \mathrm{~km}^{2}\right)$ and another for the MSI $\left(217 \mathrm{~km}^{2}\right)$ intercalibration area. With these sets of regular points, the spectral information of the sensors (LISS III, MSI and OLI) was extracted.

For the validation of the models two new sets of 50.000 points were generated, hereinafter referred to as validation samples, one for each modeling, OLI-LISS III and OLI-MSI. These sets were generated randomly for the two intercalibration areas. From the extraction of the spectral data for the three sensors, the statistical analyses were carried out before and after the intercalibration of the bands present in the LISS III and MSI sensors, using the validation samples for the two areas. Before the intercalibration, it was necessary to perform an aggregation in the pixels from the LISS III and MSI sensors, and the spatial resolution of 30m was set to be compatible with the OLI sensor (Filgueiras et al., 2020).

\section{Statistical Analysis}

After the extraction of the spectral band information, the fitted models were validated. These values were compared to the observed values of OLI reflectance obtained previously through the extraction by a grid of random points.

From the predicted and observed values, the following indices were calculated: Root Mean Square Error (RMSE) (Kennedy; Neville, 1986), Nash-Sutcliffe Efficiency (NSE) index (Nash; Sutcliffe, 1970), mean bias error (MBE) (Willmott; Matsuura, 2005), and mean absolute error (MAE) (Chai; Draxler, 2014), according to Equations 6, 7, 8 and 9.

$$
\mathrm{RMSE}=\sqrt{\frac{1}{n} \sum\left(O_{i}-P_{i}\right)^{2}}
$$




$$
\begin{aligned}
& \mathrm{NSE}=1-\frac{\sum_{i=1}^{n}\left(O_{i}-P_{i}\right)^{2}}{\sum_{i=1}^{n}\left(O_{i}-\bar{O}\right)^{2}} \\
& \mathrm{MAE}=\frac{1}{n} \sum|P i-O i| \\
& \mathrm{MBE}=\frac{1}{n} \sum(P i-O i)
\end{aligned}
$$

where: $\mathrm{Pi}$-value predicted by the model; Oi-observed value of reflectance (OLI); $\overline{\mathrm{O}}$ - mean of observed values of reflectance (OLI); $n$ - number of data pairs.

RMSE provides a measure of the accuracy of the model through the quadratic difference between the estimated and observed data, while MAE provides an average value of the absolute errors, differing from RMSE, which gives a relatively high weight to errors of great magnitude. This means that RMSE should be more useful when large errors are particularly undesirable, and MBE indicates possible underestimation or overestimation trends. NSE is used to evaluate the predictive power of the model, which can vary between $\infty$ and 1 ; the value 1 corresponds to the perfect fit between the data estimated by the model and the observed data, values between 0 and 1 are generally considered as an acceptable level of performance, and values below 0 indicate that the observed average value predicts better than the model, indicating unacceptable performance (Bakšić; Bakšić; Jazbec, 2017; Keshtegar et al., 2016; Keshtegar; Mert; Kisi, 2018; Keshtegar; Piri; Kisi, 2016; Leach; Moore, 2017; Lorenzo et al., 2017; Moriasi et al., 2007).

\section{Data application}

In order to apply the acquired models and to verify the changes before and after the intercalibration, we proceeded with the calculation of the NDVI (Normalized Difference Vegetation Index), which can be calculated by Equation 10 (Rouse et al. 1973).

$$
\mathrm{NDVI}=\frac{\left(\rho_{\mathrm{nir}}-\rho_{\mathrm{r}}\right)}{\left(\rho_{\mathrm{nir}}+\rho_{\mathrm{r}}\right)}
$$

where: pnir - reflectance of the near infrared band and $\rho r$ - reflectance in the red band. The NDVI has a response amplitude ranging from -1.0 to 1.0; for more information consult Formaggio; Sanches, (2017); Ponzoni et al. (2012); Rouse et al. (1973). 


\section{RESULTS}

Figure 4 shows the models generated from the relations between the reflectance of the OLI x LISS III spectral bands. This model has a high coefficient of determination $\left(r^{2}\right)$, with all $p$-values smaller than $2 \times 10^{-16}$, making the regression significant at 99\%. Thus, the bands 3, 4, 5, and 6 of Landsat-8/OLI reflectance are explained by the regression generated along the same lines with the spectral reflectance for bands $2,3,4$ and 5 of ResourceSat-II / LISS III in 84.52\%, 85.53\%, 84.00\% and 84.16\%, respectively (Figure 4). Band 5 of LISS III, corresponding to band 6 of $\mathrm{OLI}$, was the one with the highest $\mathrm{r}^{2}$, although there are differences in the spectral bands captured by each sensor for these bands, as can be observed in Table 1 . It should be noted that the points with high reflectance values found for the green and red spectra, in both platforms analyzed, which can be seen in Figures $4 A$ and $4 B$, do not refer to anomalies or the presence of clouds, but to an urban area, inserted in the surrounding rectangle, used for data intercalibration.

Figure 4. Regressions between OLI (y) and LISS III ( $\mathrm{x}$ ) sensor bands.
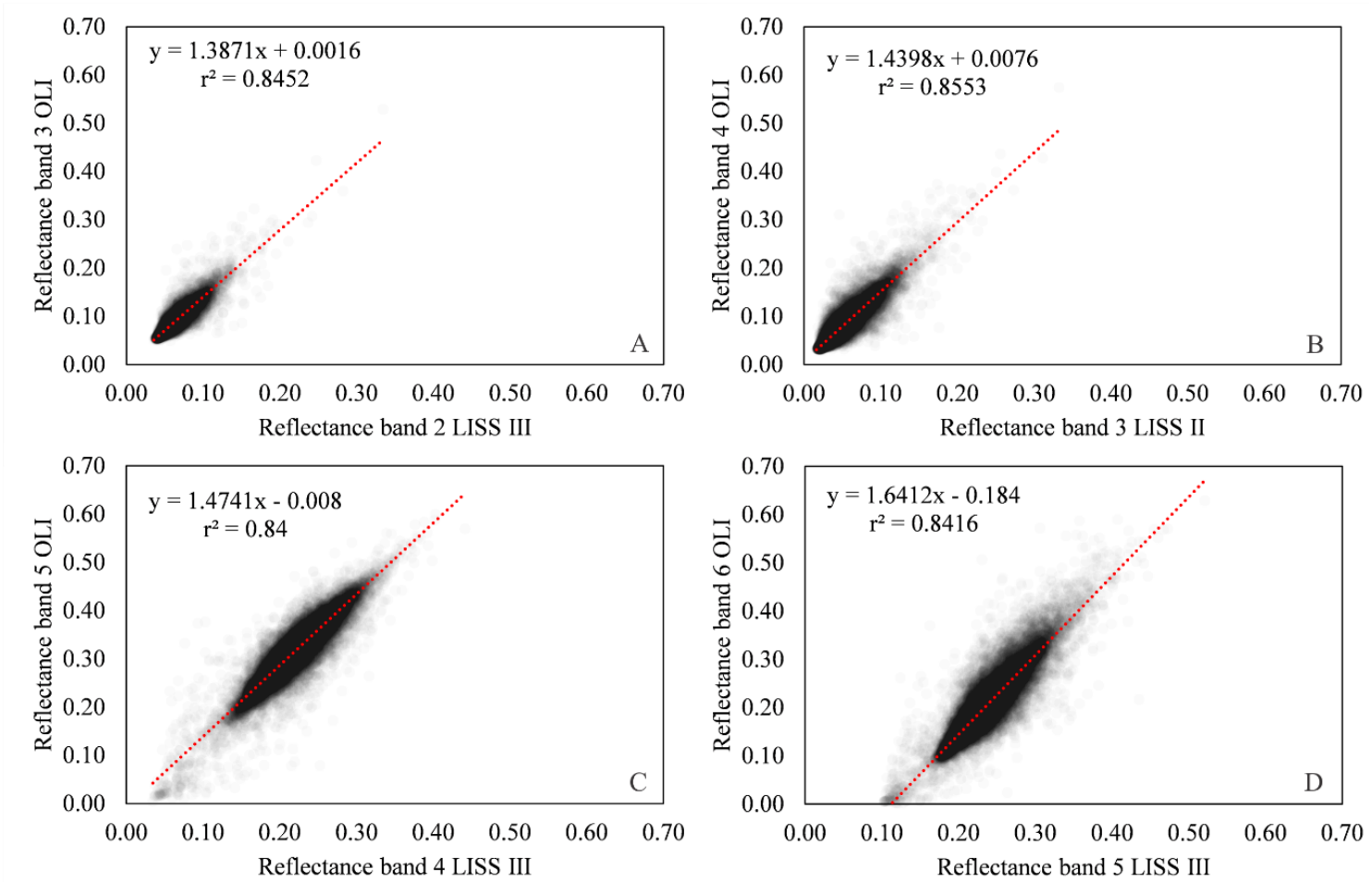

Source: authors.

Figure 5 shows the results of the regressions carried out with the OLI sensor reflectance, as dependent variables, with the reflectance referring to the MSI sensor bands, as independent variables. The regression generated through the reflectance in the OLI $\times$ MSI had a greater capacity to explain the variation of the 
reflectance belonging to the OLI sensor when compared to the analysis performed for the LISS III sensor. The $r^{2}$ values for the reflectance of the MSI sensor as independent variables were high, with the lowest being 0.8274 , referring to band 8 of the MSI sensor, and the highest $r^{2}$ being 0.9377 , for band 11 . It is emphasized that all $p$-values were lower $2 \times 10^{-16}$, causing the regression to be significant at $99 \%$. The values of the determination coefficients and the agreement for the variability between the reflectances (Figure 5) show the relationship between these two sensors.

Figure 5. Regressions between the OLI (y) and MSI (x) sensor bands.
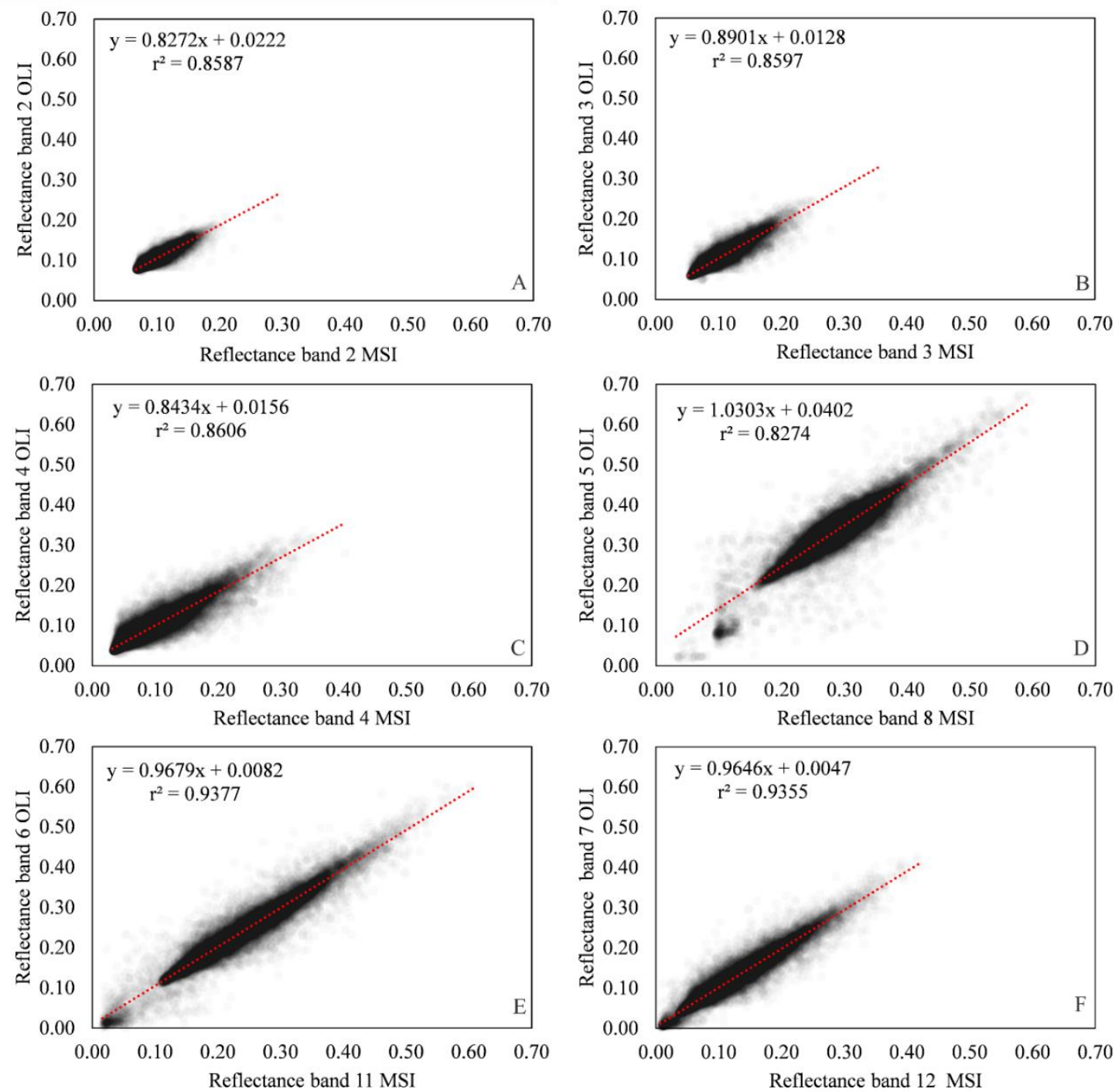

Source: authors.

Figure 6 shows the statistical indices calculated from the reflectance image of the OLI sensor with the reflectance images of LISS III, before and after intercalibration. The purpose of this information is to explain how better and more compatible the LISS III reflectances became after the adjustments made as a function of the OLI sensor. 
Figure 6. Statistical indices between LISS and OLI reflectance measurements before and after LISS III sensor intercalibration: Root Mean Square Error - RMSE (A); Nash-Sutcliffe efficiency - NSE (B); Mean Absolute Error - MAE (C) and Mean Bias Error - MBE (D).
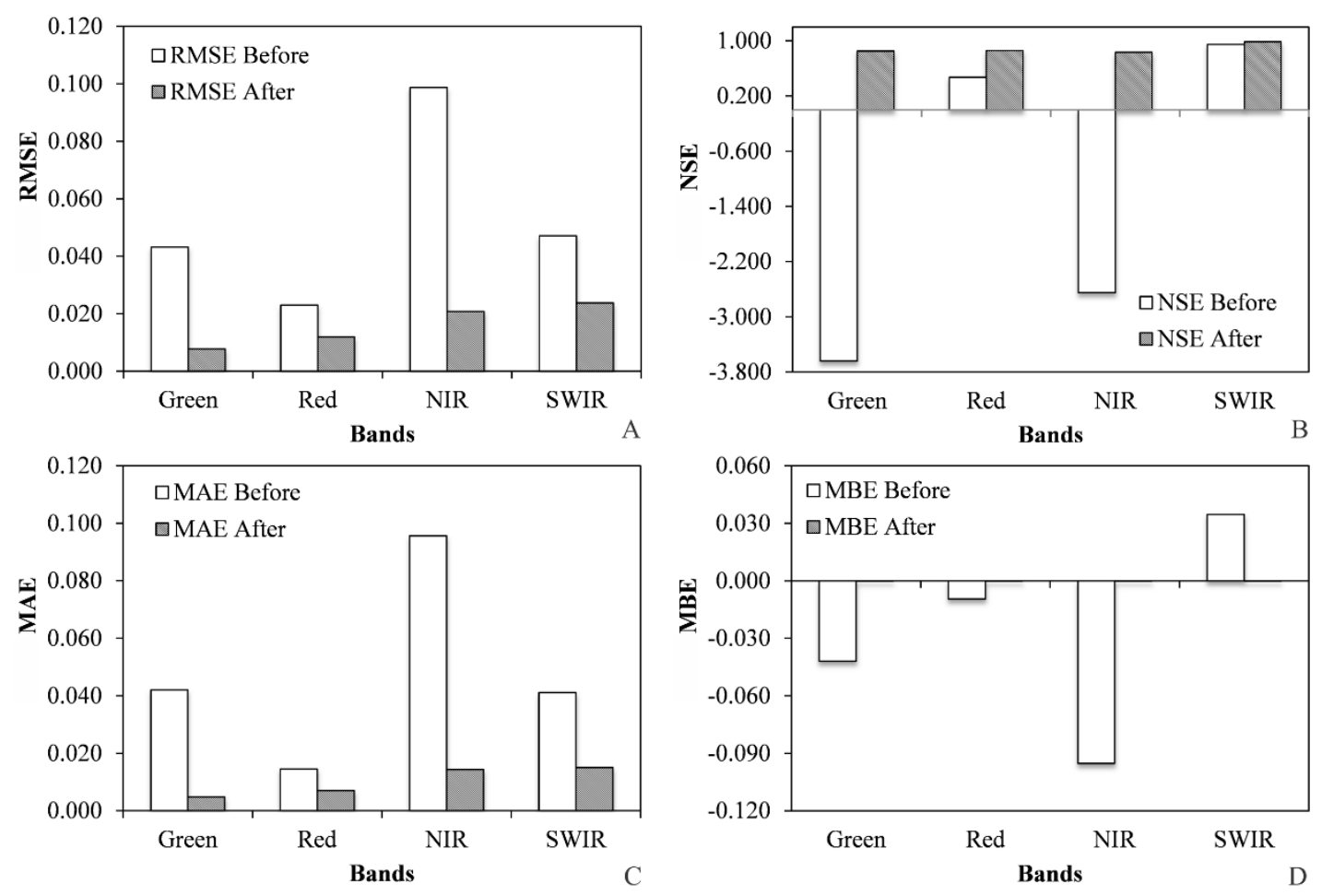

Source: authors.

The RMSE values of all LISS III reflectances were reduced after the intercalibrations were carried out, which indicates that the calibrated data gained accuracy. It is evident the difference presented by the NSE, before and after the intercalibration of the LISS III, especially with regard to the bands of blue, red, near infrared. Prior the intercalibration, these bands had negative NSE values, which are considered to be unacceptable, which did not occur after the intercalibration.

The MAE represents the average distance of the OLI reflectance difference (observed) with those from the LISS III before and after the intercalibration. After the intercalibration of the LISS III sensor, the MAE value was reduced for all the spectral bands. The negative MBE indicates that the model tends to underestimate the final result; the closer to zero, the better will be the estimation carried out by the model. Note that the mean distance between the data was reduced, being close to the null value.

Figure 7 shows the statistical indices calculated between the OLI sensor reflectance images with the MSI sensor reflectance images before and after the intercalibrations. The values of the statistical indices, before the intercalibration and after the intercalibration, have changed subtly, demonstrating the great compatibility between the sensors. The NSE before the intercalibration already has positive values, which are considered 
acceptable; however, the values after the intercalibration are higher, resulting in better results; i.e. closer to the values obtained in the OLI sensor.

Figure 7. Statistical indices between MSI and OLI reflectance measurements before and after MSI sensor intercalibration: Root Mean Square Error - RMSE (A); Nash-Sutcliffe efficiency - NSE (B); Mean Absolute Error - MAE (C) and Mean Bias Error - MBE (D)
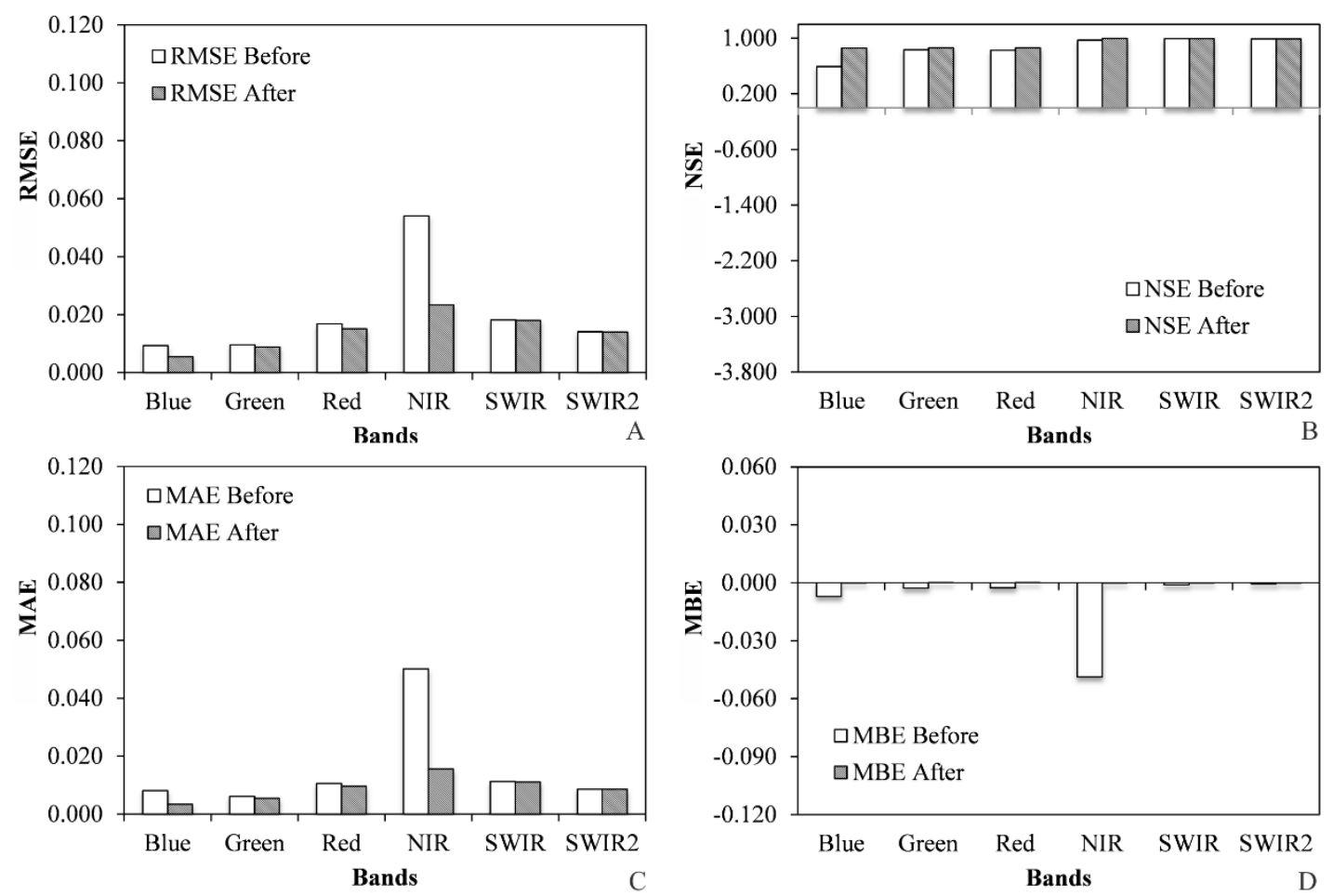

Source: authors.

In order to apply the data using multiple sensors and to have a higher frequency of images, the NDVI (Figure 8) was calculated with the OLI sensor (A), the calibrated LISS III sensor (B) and the original NDVI LISS III (C). In Figure 8 it is possible to observe the histograms of the NDVI differences of the OLI sensor with the NDVI before (D) and after the intercalibration (E). The NDVI LISS III image tends to have a higher NDVI value, which can be verified by the presence of darker green color when compared to the NDVI of the OLI sensor. After the intercalibration of LISS III, a greater similarity between the image intercalibrated with the NDVI OLI image is observed, which can be verified by the differences presented in the histograms of Figures 8D and 8E. We can observe, in general, that the frequency of pixels with NDVI difference values close to zero increased significantly when analyzed in Figures $8 \mathrm{D}$ and $8 \mathrm{E}$. 
Figure 8 - (A) NDVI image of OLI sensor; (B) NDVI image with calibrated reflectances; (C) NDVI image of LISS III sensor with original reflectances; (D) histogram of the NDVI difference from OLI and LISS III sensors before the intercalibration and (E) histogram of the NDVI difference from OLI and LISS III sensors after the intercalibration.
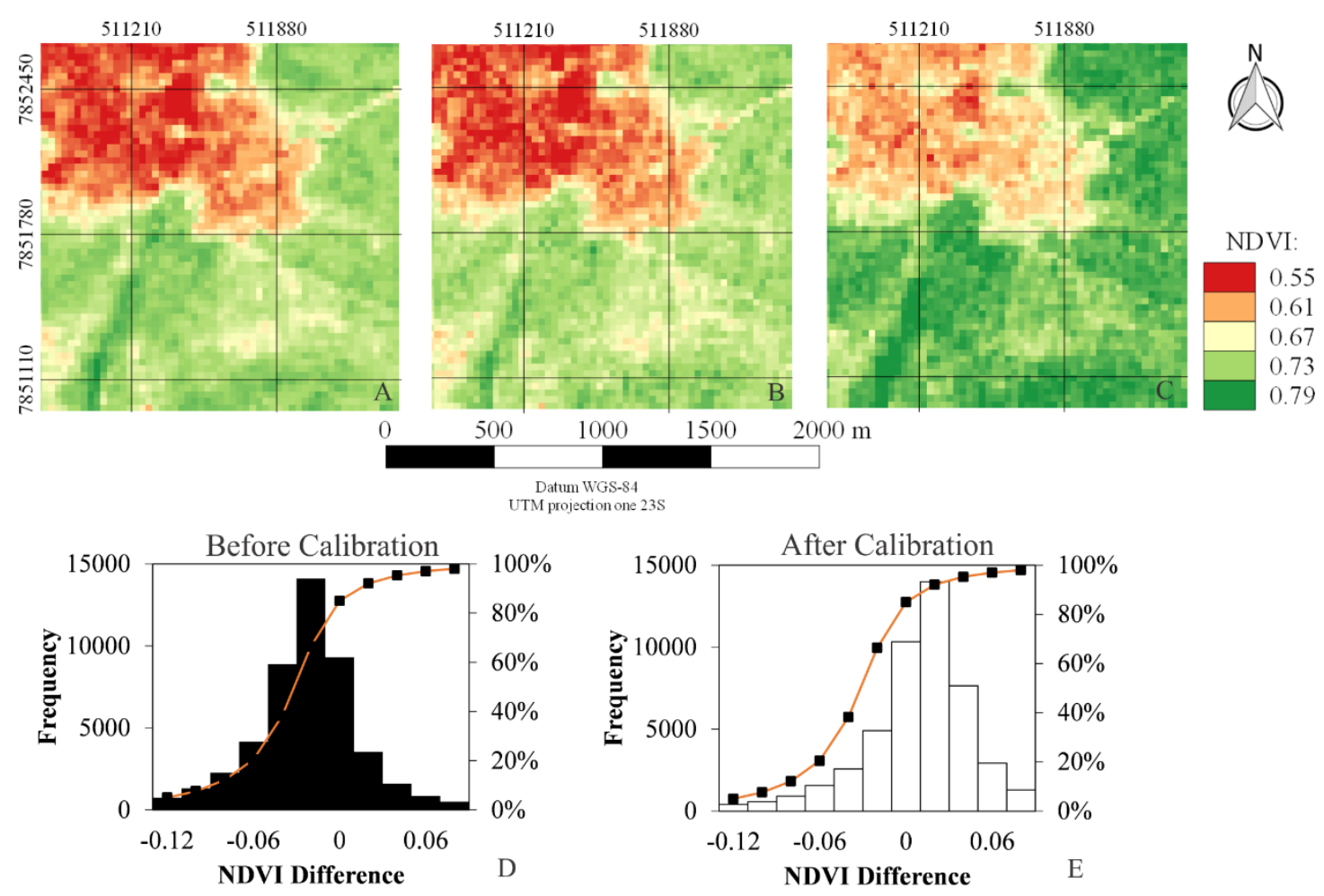

Source: authors.

Figure 9 shows NDVI images calculated with the OLI sensor (A), with the calibrated MSI sensor (B) and the original MSI NDVI image (C), and also shows the histograms of the NDVI differences, from the OLI sensor with the NDVI, before (D) and after the intercalibration (E). Generally in the area where the NDVI was calculated, the MSI sensor tends to overestimate the NDVI value when compared to the OLI sensor, which is confirmed through Figure 9D, where the highest sample frequencies of the NDVI differences from OLI and MSI are negative. The calibrated NDVI MSI (Figure 9B) has NDVI values more similar to those of NDVI OLI, which can be noted by the similarities between Figures 9A and 9B. The frequency of pixels with NDVI difference values close to zero increased significantly when analyzed in Figures 9D and 9E. 
Figure 9- (A) NDVI image of OLI sensor OLI; (B) NDVI image with calibrated reflectances; (C) Original NDVI image of MSI sensor; (D) histogram of the NDVI difference from OLI and LISS III sensors before the intercalibration and (E) histogram of the NDVI difference from OLI and LISS III sensors after intercalibration (E).
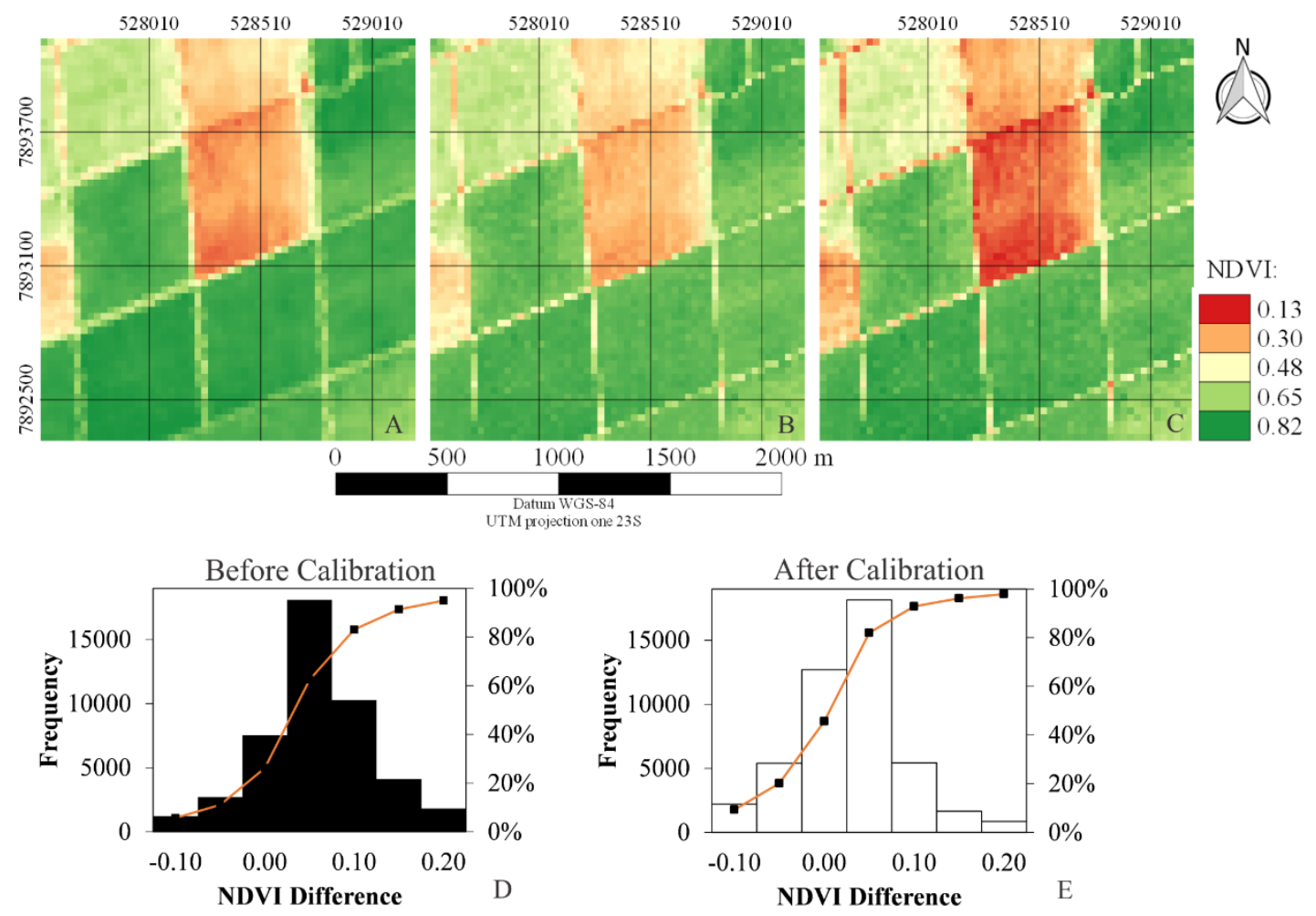

Source: authors.

Figure 10 shows the increase of image frequency when the three sensors are integrated and can be used together.

Figure 10. Passage times of the sensors for the study area, during the year 2017: A- LISS III sensor; B- MSI sensor; C - OLI sensor and D - all three sensors together.

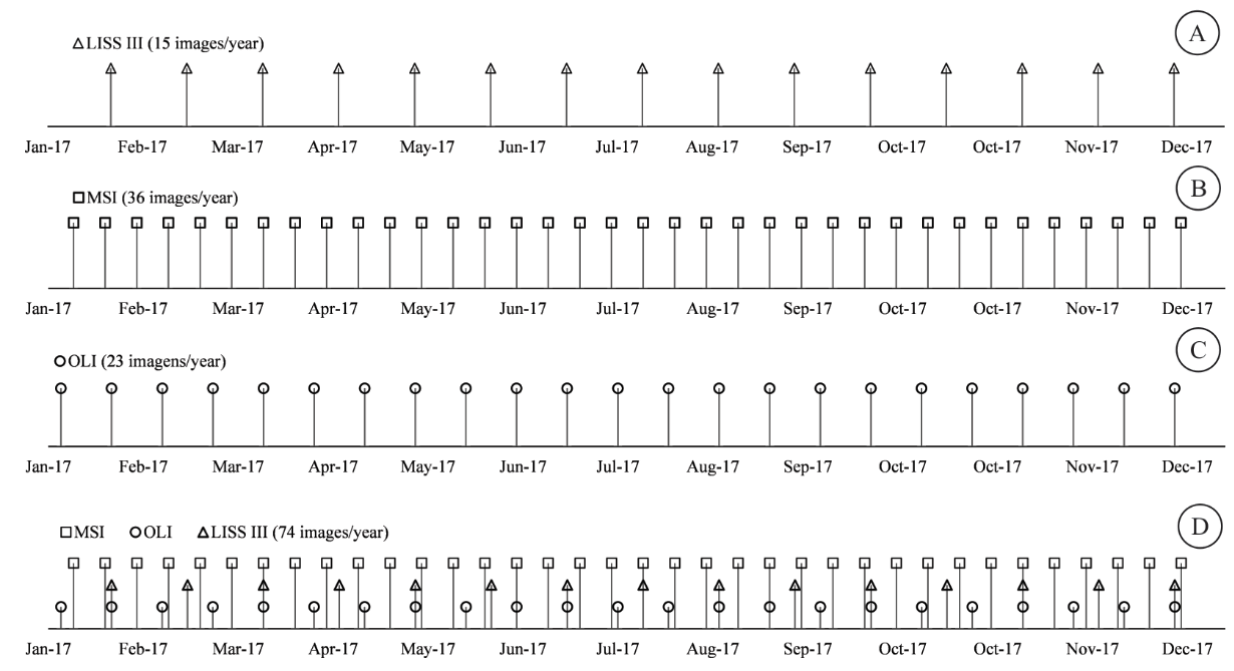

Source: authors. 
Using the three sensors together, up to 60 images can be obtained on different days for 2017, whereas when using only one satellite, maximum values of 15 (LISS III), 23 (OLI), or 36 (MSI) images can be obtained on different days.

\section{DISCUSSION}

Comparing the angular coefficients in the models generated between the OLI $(\mathrm{Y})$ and MSI $(\mathrm{X})$ sensors (Figure 5) and those generated by the regressions given by the OLI (Y) and LISS III (X) sensors (Figure 4), it is noted that the angular coefficients of the MSI sensor are closer to the unity. This fact will lead to a higher $r^{2}$ for the modeling using the MSI sensor, compared to those present in the relationship with the other sensors. However, it is important to note that both sensors responded to the variations of OLI sensor spectral responses.

It should be noted that the images present in the LISS III sensor are not available with georeferencing as it happens with the images of the Landsat and Sentinel platforms, which may have affected the intercalibration results in part, although the bands from the LISS III were georeferenced with a mean error of 0.4342 pixels with 64 points using a first-order polynomial transformation based on the images from the OLI sensor. Even with this obstacle, the images of the LISS III sensor were shown to be predictive, when the intention is to obtain the reflectance of $\mathrm{OLI}$ sensor.

The intercalibration of the LISS III and MSI sensors was carried out in order to allow the integration of different sensors in agricultural monitoring and in areas that require a greater frequency of observations, since the three sensors have medium spatial resolutions and make it possible to obtain important information of the surface area. However, if these sensors are not calibrated, they are not completely compatible, as seen in Figures 8 and 9, not serving to be integrated in a single analysis, in order to obtain information with greater temporal coverage about the object to be analyzed.

D'Odorico et al. (2013) carried out studies aiming to adjust data from the MSI sensor with data from historical collections, in order to continue the monitoring of the terrestrial surface. These authors found differences greater than $30 \%$ in the red reflectance of the MSI sensor when compared to the Advanced Very High Resolution Radiometer (AVHRR 9) and Vegetation 1 (VGT1). This dissimilarity transmitted a difference on the order of $10 \%$ when comparing the NDVI MSI with the NDVI of these sensors. After intercalibration, which was done using univariate and multivariate regression methods, these same authors found differences between the MSI sensor and these sensors of 6\%, 3\% and 7\% for red, infrared and NDVI reflectance data, respectively. All the other sensors calibrated in this study reached differences in reflectances and NDVI less than 5\%, except for AVHRR9. The sensors tested in this study were: National Oceanic and Atmospheric 
Administration (NOAA)/Advanced Very High Resolution Radiometer (AVHRR9), Landsat 7 Enhanced Thematic Mapper Plus (ETM+), Satellite Pour l'Observation de la Terre VEGETATION1 (VGT1), Moderate Resolution Imaging Spectroradiometer (MODIS), and Medium Resolution Imaging Spectrometer (MERIS). The results obtained by these authors show that the responses from the sensors are significantly different, with this difference being considered when integrating the NDVI data of the MSI sensor with those of the other sensors tested.

Storey et al. (2016) detail the similar spectral characteristics between the MSI and OLI sensors, highlighting the temporal improvement obtained using the two instruments when integrated. There are some obstacles that can be complicating in the intercalibration of these sensors, such as those described by Storey et al. (2016).

It is important to emphasize the possibility of calibrating the images along the monitoring, since an easyto-execute model has been adjusted and can be improved along the satellite passages. A fact that should be highlighted as well is the possibility to plan through Figure 10, or with similar methodology, the coincident dates of passage between the OLI and LISS III and between OLI and MSI, or the coincident dates of the passages of the three satellites, aiming at an improvement and verification of the adjustment of the models. In the present study, it was observed from Figure 10 that six dates coincided with the passage of LISS III with OLI above the study area and two dates coincided with the passage of the three satellites.

Goward et al. (2012), aiming to complement the satellite monitoring, used TM (Thematic Mapper) and ETM + (Enhanced Thematic Mapper) sensors and compared with the Indian sensor AWiFS (Advanced Wide Field Sensor). This approach has as main focus to analyze the radiometric, geometric and spectral aspects of the sensors. These authors concluded that the sensors on board the Landsat satellites have considerable differences in the configurations and operation, and the biggest differences are found in the spectral configuration of the sensors and the area captured by each sensor. In comparison between the sensors, Goward et al. (2012) found that the visible images are similar, but the same does not happen in the medium infrared region. In spite of the dissimilarities found by these authors, they consider that these differences do not limit the possibility of sensor coupling for analyses focused on forests and agriculture. This fact reinforces the importance of adjusting the sensors, against each other, for studies aiming at the acquisition of biophysical information of the landscape. In the present study, it was not observed discrepancy for the medium infrared bands, for both the LISS III and the MSI sensors, since in general, all the spectral bands had high $\mathrm{r}^{2}$.

In the present study the LISSIII sensor had a high coefficient of determination $\left(r^{2}\right)$ for all the bands. When modeled with the OLI sensor, the bands that had higher $r^{2}$ were referring to the visible region, but the results were similar. 
Berra; Fontana; Kuplich (2017), in a study with estimated volume of wood, reported that the LISS III sensor has similar sensitivity to that of the TM sensor and stated that both have similar performance for this purpose. The same authors, based on the results found in their studies, concluded that the LISSIII sensor can be used as a complement and as a substitute for the TM sensor, at least for estimates of biophysical variables; however, it should be noted that there may be differences, mainly at the pixel level.

The findings of Berra; Fontana; Kuplich (2017) reinforce the importance of the inter-sensor intercalibration and the compatibility analysis between the sensors, according to what is discussed in this study. Therefore, the available information of the sensor should be used, but information from different sources should be used with caution and rationality.

\section{CONCLUSIONS}

The intercalibrations of the reflectance images of the LISS III and MSI sensors with the OLI sensor as reference enables the coupling of satellites to increase the frequency and availability of information in studies that require a greater amount of observations, such as in agricultural monitoring, natural disasters, deforestation, among others.

The intercalibration among the sensors carried out in this study increases the chance of success in agricultural monitoring for crops with a short phenological cycle, since the availability of compatible images among them increased substantially.

An important fact that should be emphasized is the simplicity of the fitted models (simple linear regression) in the present study, which have a direct application, besides being feasible in practical approaches.

It is important to note that, in addition to the simplicity of the fitted models, these can still be adjusted along the dates that the satellites match the passages, that is, the models can gain robustness in the accuracy of their predictions throughout the monitoring.

It should be noted that with the launch of the Sentinel-2B satellite in 2017, which also has the MSI sensor, as well as the Sentinel-2A platform, there will be the possibility of raising the temporal resolution even further by coupling the satellite to the platforms already calibrated in this study. 


\section{ACKNOWLEDGEMENTS}

The authors would like to thank Conselho Nacional de Desenvolvimento Científico e Tecnológico - Brazil (CNPq), grant number: 148636/2016-0 and Coordenação de Aperfeiçoamento de Pessoal de Nível Superior Brazil (CAPES) for the financial support (finance code: 001), resources provided and grant.

\section{REFERÊNCIAS}

ARIZA, A. Descripción y Corrección de Productos Landsat 8 LDCM (Landsat Data Continuity Mission). Bogotá: Instituto Geográfico Agustín Codazzi, 2013. 46p.

BAKŠIĆ, N.; BAKŠIĆ, D.; JAZBEC, A. Hourly fine fuel moisture model for Pinus halepensis (Mill.) litter. Agricultural and Forest Meteorology, v.243, p.93-99, 2017.https://doi.org/10.1016/j.agrformet.2017.04.014

BALTHAZAR, V.; VANACKER, V.; LAMBIN, E. F. Evaluation and parameterization of ATCOR3 topographic correction method for forest cover mapping in mountain areas. International Journal of Applied Earth Observation and Geoinformation, v.18, p.436-450, 2012.https://doi.org/10.1016/j.jag.2012.03.010

BERRA, E. F.; FONTANA, D. C.; KUPLICH, T. M. Comparison of satellite imagery from LISS-III/Resourcesat-1 and TM/Landsat 5 to estimate stand-level timber volume. Pesquisa Florestal Brasileira, v.36, p.363-373, 2017.https://dx.doi.org/10.4336/2016.pfb.36.88.1134

BERTOLIN, N. DE O. et al. Predição da produtividade de milho irrigado com auxílio de imagens de satélite. Revista Brasileira de Agricultura Irrigada, v.11, p.1627-1638, 2017.https://dx.doi.org/10.7127/rbai.v11n400567

CHANDER, G. et al. Cross-comparison of the IRS-P6 AWiFS sensor with the L5 TM, L7 ETM+, \& Terra MODIS sensors. Disponível em: <http://proceedings.spiedigitallibrary.org/proceeding.aspx?doi=10.1117/12.830502>. Acesso em: 4 ago. 2017

CHAI, T.; DRAXLER, R. R. Root mean square error (RMSE) or mean absolute error (MAE)? - Arguments against avoiding RMSE in the literature. Geoscientific Model Development, v. 7, n. 3, p. 1247-1250, 30 jun. 2014.

CHEN, B. et al. Spatially and Temporally Weighted Regression: A Novel Method to Produce Continuous Cloud-Free Landsat Imagery. IEEE Transactions on Geoscience and Remote Sensing, v.55, p.27-37, 2017.https://dx.doi.org/10.1109/TGRS.2016.2580576

COLBY, J. D. Topographic normalization in rugged terrain. Photogrammetric Engineering and Remote Sensing, v.57, p.531-537, 1991.

LIMA, R. N. S.; RIBEIRO, C. B. M. Comparação de métodos de correção topográfica em imagens Landsat sob diferentes condições de iluminação. Revista Brasileira de Cartografia, v.5, p. ,2014.

D'ODORICO, P. et al. Experimental Evaluation of Sentinel-2 Spectral Response Functions for NDVI Time-Series Continuity. IEEE Transactions on Geoscience and Remote Sensing, v.51, p.1336-1348, 2013.

https://dx.doi.org/10.1109/TGRS.2012.2235447

DRUSCH, M. et al. Sentinel-2: ESA's Optical High-Resolution Mission for GMES Operational Services. Remote Sensing of Environment, v.120,p.25-36, 2012.https://doi.org/10.1016/j.rse.2011.11.026

FAN, X.; LIU, Y. A Generalized Model for Intersensor NDVI Calibration and Its Comparison With Regression Approaches. IEEE Transactions on Geoscience and Remote Sensing, v.55, p.1842-1852, 2017.https://dx.doi.org/10.1109/TGRS.2016.2635802

FERNÁNDEZ-MANSO, A.; FERNÁNDEZ-MANSO, O.; QUINTANO, C. SENTINEL-2A red-edge spectral indices suitability for discriminating burn severity. International Journal of Applied Earth Observation and Geoinformation, v.50, p.170-175, 2016.https://doi.org/10.1016/j.jag.2016.03.005

GAO, F.; KUSTAS, W.; ANDERSON, M. A Data Mining Approach for Sharpening Thermal Satellite Imagery over Land. Remote Sensing, v.4, p.3287-3319, 2012.https://doi.org/10.3390/rs4113287

GASCON, F. et al. Copernicus Sentinel-2A Calibration and Products Validation Status. Remote Sensing, v. 9, n. 6, p. 584,10 jun. 2017.

GOWARD, S. N. et al. Complementarity of ResourceSat-1 AWiFS and Landsat TM/ETM+ sensors. Remote Sensing of Environment, v.123, p.41-56, 2012.https://doi.org/10.1016/j.rse.2012.03.002 
FILGUEIRAS, R. et al. Fusion of MODIS and Landsat-Like Images for Daily High Spatial Resolution NDVI. Remote Sensing, v. 12, n. 8, p. 1297, 20 abr. 2020.

FORMAGGIO, A. R.; SANCHES, I. D. Sensoriamento remoto em agricultura. São Paulo: Oficina de Textos, 2017, 284p.

HANTSON, S.; CHUVIECO, E. Evaluation of different topographic correction methods for Landsat imagery. International Journal of Applied Earth Observation and Geoinformation, v.13, p.691-700, 2011.https://doi.org/10.1016/j.jag.2011.05.001

IRONS, J. R.; DWYER, J. L.; BARSI, J. A. The next Landsat satellite: The Landsat Data Continuity Mission. Remote Sensing of Environment, v.122, p.11-21, 2012.https://doi.org/10.1016/j.rse.2011.08.026

JENSEN, J. R.; EPIPHANIO, J. C. N. Sensoriamento remoto do ambiente: uma perspectiva em recursos terrestres. São José dos Campos, SP: Parêntese, 2011. 598p.

JIMÉNEZ-MUÑOZ, J. C. et al. Atmospheric correction of optical imagery from MODIS and Reanalysis atmospheric products. Remote Sensing of Environment, v.114, p. 2195-2210, 2010.https://dx.doi.org/10.1016/j.rse.2010.04.022

KENNEDY, J. B.; NEVILLE, A. M. Basic statistical methods for engineers and scientists. New York: Harper \& Row, 1986.

KESHTEGAR, B. et al. Optimized River Stream-Flow Forecasting Model Utilizing High-Order Response Surface Method. Water Resources Management, v.30, p.3899-3914, 2016.https://doi-org.ez35.periodicos.capes.gov.br/10.1007/s11269-016-1397-4

KESHTEGAR, B.; MERT, C.; KISI, O. Comparison of four heuristic regression techniques in solar radiation modeling: Kriging method vs RSM, MARS and M5 model tree. Renewable and Sustainable Energy Reviews, v.81, p.330-341, 2018.https://doi.org/10.1016/j.rser.2017.07.054

KESHTEGAR, B.; PIRI, J.; KISI, O. A nonlinear mathematical modeling of daily pan evaporation based on conjugate gradient method. Computers and Electronics in Agriculture, v.127, p.120-130, 2016.https://doi.org/10.1016/j.compag.2016.05.018

KOBAYASHI§, S.; SANGA-NGOIE, K. A comparative study of radiometric correction methods for optical remote sensing imagery: the IRC vs. other image-based C-correction methods. International Journal of Remote Sensing, v.30, p.285-314, 2009.https://doi.org/10.1080/01431160802356781

$\mathrm{EACH}$, J. A.; MOORE, D. Insights on stream temperature processes through development of a coupled hydrologic and stream temperature model for forested coastal headwater catchments: Stream temperature processes in headwater catchments. Hydrological Processes, v.31, p.3160-3177, 2017.https://doi-org.ez35.periodicos.capes.gov.br/10.1002/hyp.11190

LI, P.; JIANG, L.; FENG, Z. Cross-Comparison of Vegetation Indices Derived from Landsat-7 Enhanced Thematic Mapper Plus (ETM+) and Landsat-8 Operational Land Imager (OLI) Sensors. Remote Sensing, v.6, p.310-329, 2013.https://doi.org/10.3390/rs6010310

LORENZO, A. T. et al. Optimal interpolation of satellite and ground data for irradiance nowcasting at city scales. Solar Energy, v.144, p.466-474, 2017.https://doi.org/10.1016/j.solener.2017.01.038

MAO, D. et al. Integrating AVHRR and MODIS data to monitor NDVI changes and their relationships with climatic parameters in Northeast China. International Journal of Applied Earth Observation and Geoinformation, v.18, p.528-536, 2012.https://doi.org/10.1016/j.jag.2011.10.007

MORIASI, D. N. et al. Model evaluation guidelines for systematic quantification of accuracy in watershed simulations. Transactions of the ASABE, v.50, p.885-900, 2007.https://dx.doi.org/10.13031/2013.23153

NASH, J. E.; SUTCLIFFE, J. V. River flow forecasting through conceptual models: Part I - A discussion of principles. Journal of Hydrology, v. 10, n. 3, p. 282-290, abr. 1970.

NAVALGUND, R. R.; JAYARAMAN, V.; ROY, P. S. Remote sensing applications: An overview. Current Science, v.93, p.1747-1766, 2007.

PANDYA, M. R.; MURALI, K. R.; KIRANKUMAR, A. S. Quantification and comparison of spectral characteristics of sensors on board Resourcesat-1 and Resourcesat-2 satellites. Remote Sensing Letters, v.4, p.306-314, 2013.https://doi.org/10.1080/2150704X.2012.727491

PANDYA, M. R.; SINGH, R. P.; CHAUDHARI, K. N.; MURALI, K. R.; KIRANKUMAR, A. S.; DADHWAL, V. K.; PARIHAR, J. S. Spectral characteristics of sensors onboard IRS-1D and P6 satellites: Estimation and their influence on surface reflectance and NDVI. Journal of the Indian Society of Remote Sensing, v. 35, n. 4, p. 333-350, 2007.

PANDYA, M. R.; SINGH, R. P.; MURALI, K.; BABU, P.; KIRANKUMAR, A.; DADHWAL, V. K. Bandpass solar exoatmospheric irradiance and Rayleigh optical thickness of sensors on board Indian remote sensing satellites-1B,-1C,-1D, and P4.

IEEE Transactions on Geoscience and Remote Sensing, v. 40, n. 3, p. 714-718, 2002. 
PONZONI, F.; SHIMABUKURO, Y.; KUPLICH, T. Sensoriamento remoto da vegetação. São Paulo: Oficina de Textos, 2012.160 p.

RIANO, D. et al. Assessment of different topographic corrections in Landsat-TM data for mapping vegetation types (2003). IEEE Transactions on Geoscience and Remote Sensing, v.41, p.1056-1061, 2003.https://dx.doi.org/10.1109/TGRS.2003.811693

OY, D. P. et al. Landsat-8: Science and product vision for terrestrial global change research. Remote Sensing of Environment, v.145, p.154-172, 2014.https://doi.org/10.1016/j.rse.2014.02.001

ROUSE, J.W., HASS, R.H., SCHELL, J.A., DEERING, D.W. Monitoring vegetation system in the great plains with ERTS. Third ERTS Symposium [S.I]. NASA. 1973. pp. 309-317.

SETH, H. et al. Pre-flight radiometric and spectral calibration of Resourcesat-2A-LISS3* payload. Disponível em: <http://proceedings.spiedigitallibrary.org/proceeding.aspx?doi=10.1117/12.2223795>. Acesso em: 4 ago. 2017

STOREY, J. et al. A note on the temporary misregistration of Landsat-8 Operational Land Imager (OLI) and Sentinel-2 Multi Spectral Instrument (MSI) imagery. Remote Sensing of Environment, v.186, p.121-122, 2016.https://doi.org/10.1016/j.rse.2016.08.025

SZANTOI, Z.; SIMONETTI, D. Fast and Robust Topographic Correction Method for Medium Resolution Satellite Imagery Using a Stratified Approach. IEEE Journal of Selected Topics in Applied Earth Observations and Remote Sensing, v.6, p.1921-1933, 2013.https://dx.doi.org/10.1109/JSTARS.2012.2229260

TEILLET, P. M. et al. Radiometric cross-calibration of the Landsat-7 ETM+ and Landsat-5 TM sensors based on tandem data sets. Remote sensing of Environment, v.78, p.39-54, 2001.https://doi.org/10.1016/S0034-4257(01)00248-6

TEILLET, P. M.; GUINDON, B.; GOODENOUGH, D. G. On the slope-aspect correction of multispectral scanner data. Canadian Journal of Remote Sensing, v.8, p.84-106, 1982.https://doi.org/10.1080/07038992.1982.10855028

WILLMOTT, C.; MATSUURA, K. Advantages of the mean absolute error (MAE) over the root mean square error (RMSE) in assessing average model performance. Climate Research, v. 30, p. 79-82, 2005.

WULDER, M. A. et al. Current status of Landsat program, science, and applications. Remote Sensing of Environment, v. 225, p. 127147, maio 2019.

YAN, L. et al. An Automated Approach for Sub-Pixel Registration of Landsat-8 Operational Land Imager (OLI) and Sentinel-2 Multi Spectral Instrument (MSI) Imagery. Remote Sensing, v.8, p.520, 2016. https://doi.org/10.3390/rs8060520

ZHANG, X.; TIAN, Q. Comparison of spectral characteristics between EO-1 ALI and IRS-P6 LISS-III imagery. Current Science, v. 108, n. 5, p. 954, 2015. 